\title{
HPLC-SEC chromatograms as surrogates for BOD and other organic quality indicators of septic tank effluents
}

\author{
H. M. Szabo ${ }^{1,2}$ (D) R. Lepistö ${ }^{1}$
}

Received: 9 March 2019 / Revised: 26 July 2019 / Accepted: 27 August 2019 / Published online: 3 September 2019

(c) The Author(s) 2019

\begin{abstract}
HPLC-SEC with UV254, trytophane-like and tyrosine-like fluorescence detection was used to characterize onsite wastewater effluents from septic tanks. In total, 69 wastewater effluents, 15 of them greywater (GWE) and 54 blackwater effluents (BWE), were analysed for water quality indicators: BOD-7, DOC, COD, Total-N and TDP using conventional methods. The chromatograms showed well-separated three regions, referred to as chromatographic indicators (ChIs), which were tested as surrogates for the conventional indicators. The best surrogates for BOD-7 and DOC were found in region 3 of the tyrosine-like chromatograms. Data showed that Tyr-3, representing the sum of the tyrosine-like fractions from 8.25 min, could be used reliably to assess the BOD-7 and DOC of GWE and to approximate the BOD-7 of BWE. In addition, Tyr-3a, the fractions between 8.25 and $14 \mathrm{~min}$, could be used to approximate the DOC of BWE. Furthermore, the strong correlation between COD and Tyr (all the tyrosine-type fractions) for GWE and between COD and UV254-3 for BWE allows reliable calculation of the COD of GWEs and its approximation of BWEs by linear regression. Total-N correlated weakly with tryptophan-like fractions. The use of ChI as surrogates for BOD-7, DOC and COD is an important finding that enables reliable and fast analysis without use of harmful chemicals.
\end{abstract}

Keywords Blackwater $\cdot$ Greywater $\cdot$ Fluorescence $\cdot$ SEC $\cdot$ Ionic eluent $\cdot$ COD $\cdot$ DOC

\section{Introduction}

Septic tanks are worldwide the most common systems for treating household wastewaters produced in rural areas (Eveborn et al. 2012; Withers et al. 2012; Garcia et al. 2013). The septic tank, a key purification unit for treating wastewater onsite, produces under anaerobic conditions a complex mixture of partially decomposed organic and inorganic compounds (Jenssen et al. 2010; Eveborn et al. 2012; O'Launaigh et al. 2012; Garcia et al. 2013). Faulty design and lack of routine maintenance of septic systems cause the septic tank effluent to deteriorate and thereby add to health

Editorial responsibility: M. Abbaspour.

H. M. Szabo

hilda.szabo@tuni.fi

1 The Faculty of Engineering and Natural Sciences, Tampere University, P.O. Box 541, 33014 Tampere, Finland

2 School of Construction and Environmental Engineering, Tampere University of Applied Sciences, P.O. Box 356, 33101 Tampere, Finland risks and cause eutrophication of the receiving water bodies (Almomani and Khraisheh 2016). A rough estimation of an extended watershed dominated by agriculture showed that septic tank effluents contribute to as much as $14 \%$ of the total anthropogenic environmental phosphorous load (Tanik et al. 2013).

To assess the environmental loadings of organic matter and nutrients from a septic tank, fast and reliable analytical methods are necessary to characterize its effluents (STE). The conventional quality indicators used to characterize dissolved organic matter (DOM), nitrogen and phosphorous in wastewater and wastewater effluent (WWE) are 7-day biochemical oxygen demand (BOD-7), chemical oxygen demand (COD) and dissolved organic carbon (DOC) for the organic matter content, total Kjeldahl nitrogen (TKN) and total dissolved phosphorous (TDP). These indicators are all 'gross' quality indicators (sum parameters) and provide no information on particular components of organic matter. They have also other drawbacks: BOD-7 analysis is time-consuming, lasts for 7 days, and Kjeldahl and COD methods use harmful chemicals. Therefore, alternative methods are needed to replace and/or complement these conventional methods 
(Pasztor et al. 2009; Prasse et al. 2015). As we assessed in our previous study (Szabo et al. 2016), an alternative method could be aqueous, high performance, size exclusion liquid chromatography (HPLC-SEC) with multiple detection for quick information on the gross- and component organic matter content. HPLC-SEC is generally used to separate mixtures of organic compounds in water samples (biomolecules, natural organic matter) (Irvine 1997; Pelekani et al. 1999; Bouvier and Koza 2014), but it can also simultaneously be used to measure nitrate concentration in groundwater (Szabo and Tuhkanen 2010). So far, HPLC-SEC has been mainly applied to measuring the molecular weight (MW) of the fractions of organic matter mixtures, supposing a separation based solely on a size exclusion mechanism (Specht and Frimmel 2000; Figueruelo et al. 2004; Janoš and Zatrepálková 2007). However, for complex organic mixtures, such as wastewater effluents, secondary interactions occur between solute molecules and column material (Ricker and Sandoval 1996; Irvine 1997; Pelekani et al. 1999; Bouvier and Koza 2014), which interfere with correct measurements of MWs. Nevertheless, the HPLC-SEC method provides good separation and can, therefore, be used, especially with multiple detection, to characterize component organic matter: UV/VIS is suitable to detect aromatic groups present in 'humic-type' compounds and fluorescence to detect 'protein-type' compounds (Specht and Frimmel 2000; Her et al. 2003; Wu et al. 2016; Carstea et al. 2016; Szabo et al. 2016).

To ensure good separation of organic fractions in a water sample, suitable eluent at proper concentration and $\mathrm{pH}$ must be used. Our previous research showed that $\mathrm{Na}$-acetate eluent at concentrations of up to $0.03 \mathrm{M}$ with neutral or slightly basic $\mathrm{pH}$ can efficiently separate DOM fractions in a complex wastewater sample (Szabo et al. 2016). According to our knowledge, the use of these fractions as surrogates of the conventional organic water quality indicators of complex water samples has not been studied before. The main 'drawback' of the method is that, because of secondary interactions, it does not provide reliable MW measurements of the fractions of complex wastewater.

The main objectives of this research were (1) to characterize the organic matter of septic tank effluents by HPLC-SEC with a multiple detection method and (2) to develop a rapid and reliable HPLC-SEC method to determine surrogates for water quality indicators, mainly BOD-7, COD, DOC and TKN.

\section{Materials and methods}

\section{Wastewater effluent samples}

In total, 69 STEs were analysed. Samples were taken from small-scale, onsite wastewater systems serving single households in villages in western and southern Finland. In
15 cases, the wastewater was greywater (consisting only of household washing water because the households have dry toilets and produce no wastewater for treatment). In the remaining 54 cases, the treated wastewater was blackwater (mixed wastewater) containing both washing waters and toilet waters including urine and faeces. Greywater (GWE) and blackwater effluent (BWE) samples were taken from the supernatant (just under the surface) from the last compartment (second or third) of the septic tank or from the distribution wells after the septic tank carefully to avoid the occasional solids floating on the surface. In 13 cases, the septic tank effluents were further purified on site in constructed filtration fields, and the filtrates were collected in a manhole from where our samples were taken. Samples were collected in 1-L polyethylene bottles and kept at $5{ }^{\circ} \mathrm{C}$ until analysed within $24 \mathrm{~h}$ for conventional quality indicators. Each site was sampled once. For HPLC analysis, samples were quickly frozen until analysed.

\section{Methods}

\section{Chemical analyses}

The TKN of the samples was measured according to the Kjeldahl method (SFS 5505), whereas total dissolved phosphorous (TDP) was determined spectrophotometrically (SFS 3026). The organic content of the samples was measured as BOD-7, DOC and COD. BOD-7 was measured using the OxiTop OC 100 WTW system with an accuracy of $\pm 1 \%$ of the measured value and $\pm 7 \%$ of the measuring range. The samples were not diluted, because the measuring range (500-1350 hPa) was not exceeded. To prevent nitrification, allylthioureaa (ATU) was added to each sample before they were incubated at $20{ }^{\circ} \mathrm{C}$ for 7 days. BOD-7 values were directly read from the instrument.

COD was determined according to the Finnish Standard SFS 5504, using Hach Lange LT 200 Dry Thermostat, UK, for digestion followed by titration according to the method specifications. DOC was measured as non-purgeable organic carbon with a TOC analyser, the SHIMADZU TOC-5000. Before DOC analysis, the samples were filtered through a $0.45-\mu \mathrm{m}$ filter (Whatman).

\section{HPLC-SEC analyses}

HPLC-SEC analysis was done with a Hewlett-Packard HPLC 1100 system, using a TSK-GEL G3000SW $7.5 \mathrm{~mm} \times 30 \mathrm{~cm}$ column (TOSOH Bioscience). Two detectors were used in tandem: a UV/VIS HP 1100 Series Diode Array Detector (detection wavelength $254 \mathrm{~nm}$ (UV254)) and an HP 1100 Series Fluorescence Detector with two excitation/emission wavelengths set for tryptophan-like detection (Ex/Em $270 \mathrm{~nm} / 355 \mathrm{~nm}$ ) and tyrosine-like detection (with 
Ex/Em 270/310). The eluent used was $0.02 \mathrm{M} \mathrm{Na-acetate}$ with $\mathrm{pH} 7$ and a flow rate of $1 \mathrm{~mL} / \mathrm{min}$. The sample injection volume was $20 \mu \mathrm{L}$ with elution time set to $35 \mathrm{~min}$. The conditions produced good global resolution for both GWE and BWE (Szabo et al. 2016). Before analysis, the samples were filtered with a $0.45-\mu \mathrm{m}$ filter (Whatman). For each sample injection, three chromatograms were obtained, integrated manually with their peak areas used to assess organic matter in the samples. The void volume of the column (4.6 min) was determined with Blue Dextrane (molecular weight MW $=10^{6} \mathrm{Da}$, FLUKA, Switzerland), the permeation volume for UV-signals (11.6 min) was measured with acetone $(\mathrm{MW}=58 \mathrm{Da})$, and the permeation volume for tryptophan- and tyrosine-like signals (12.4 min) was measured with tryptophan, as reported previously (Szabo et al. 2016). However, we did not calibrate the column to determine molecular weight, since secondary interactions strongly affect retention times and make molecular weight calculations irrelevant (Szabo et al. 2016).

\section{Statistical analyses}

The goodness of fit to the normal distribution of data was tested with the one-sample Kolmogorov-Smirnov test. Since only 6 out of 23 examined parameters showed normal distribution, Spearman's rank correlation coefficient was used to evaluate the degree of association between the parameters. Statistical analysis was performed with the statistical program SPSS version 23 (IBM). Linear regression between correlating data was done with Excel 2016.

\section{Results and discussion}

\section{Quality of septic tanks effluent}

The mean, maximum and minimum values of the conventional quality indicators of onsite wastewater effluents are given in Table 1 . The values present great variety within
BWE and within GWE samples, depending obviously on the number and customs of the septic tank users as well as the characteristics of the onsite system.

Our TKN $(107.9 \mathrm{mg} / \mathrm{L})$ and COD $(661.9 \mathrm{mg} / \mathrm{L})$ mean values for BWE are higher than those found in the literature (Corbett et al. 2002; Jenssen et al. 2010; O'Launaigh et al. 2012, respectively). On the other hand, our results for TDP $(11.3 \mathrm{mg} / \mathrm{L})$ and BOD $(269.7 \mathrm{mg} / \mathrm{L})$ correspond with those reported in the literature (Corbett et al. 2002; Jenssen et al. 2010; O'Luanaigh et al. 2012). As expected, a clear difference can be seen between the qualities of the two types of effluents. However, the mean GWE values measured in this study (Table 1) are higher than those reported earlier in one comparative study (Brandes 1978), in which total phosphorus (TP) values of $1.4 \mathrm{mg} / \mathrm{L}$ and TKN values of $11.3 \mathrm{mg} / \mathrm{L}$ were measured in a GWE, values that were 10 times lower than the corresponding values in BWE. In our study, GWE mean values for all conventional indicators were lower than BWE means: GWE means are $24 \%$ of TDP-, $24 \%$ of TKN-, $66 \%$ of BOD-7-, $59 \%$ of COD- and $66 \%$ of DOC-BWE means (Table 1). Because environmental loading depends also on the volume of the effluents discharged, high effluent concentrations do not necessarily mean high loading. In addition to effluent concentrations, correct assessment of the loading from septic effluents must take into account the number of persons using the septic system and their water consumption. The mean biodegradability of GWE and BWE assessed as BOD-7/COD was > 0.4 (0.41 for BWE and 0.46 for GWE), which indicates biodegradable effluents (Chamarro et al. 2001), that is, effluents that will further degrade once released into the environment.

\section{Sample analysis by HPLC-SEC}

\section{Quantitative analysis}

Typical chromatograms of BWE and GWE are given in Fig. 1. The chromatograms have several and different peaks with different types of detection and show diverse
Table 1 Characteristics of blackwater effluents BWE (a) and greywater effluents GWE (b)

\begin{tabular}{|c|c|c|c|c|c|c|c|c|c|c|}
\hline & \multicolumn{5}{|l|}{$\mathrm{a}$} & \multicolumn{5}{|l|}{$\mathrm{b}$} \\
\hline & \# & Minimum & Maximum & Mean & SD & $\#$ & Minimum & Maximum & Mean & $\mathrm{SD}$ \\
\hline $\mathrm{pH}$ & 54.0 & 5.6 & 8.8 & 7.2 & 0.6 & 15.0 & 5.9 & 7.9 & 6.8 & 0.5 \\
\hline TDP (mg/L) & 54.0 & 0.4 & 31.0 & 11.3 & 6.1 & 15.0 & 0.2 & 12.7 & 2.7 & 3.2 \\
\hline TKN (mg/L) & 54.0 & 6.0 & 390.6 & 107.9 & 76.3 & 15.0 & 0.4 & 224.0 & 26.5 & 56.0 \\
\hline BOD-7 (mg/L) & 54.0 & 5.6 & 543.0 & 269.7 & 150.1 & 14.0 & 14.1 & 509.0 & 177.1 & 156.6 \\
\hline $\mathrm{COD}(\mathrm{mg} / \mathrm{L})$ & 41.0 & 41.0 & 2853.0 & 661.9 & 498.5 & 11.0 & 35.0 & 980.0 & 389.8 & 286.8 \\
\hline $\mathrm{DOC}(\mathrm{mg} / \mathrm{L})$ & 54.0 & 5.3 & 246.0 & 91.8 & 58.9 & 15.0 & 5.1 & 244.0 & 60.9 & 63.1 \\
\hline
\end{tabular}

TDP total dissolved phosphorous; $T K N$ total Kjeldahl nitrogen; $B O D-7$ biochemical oxygen demand; $C O D$ chemical oxygen demand; $D O C$ total dissolved organic carbon 

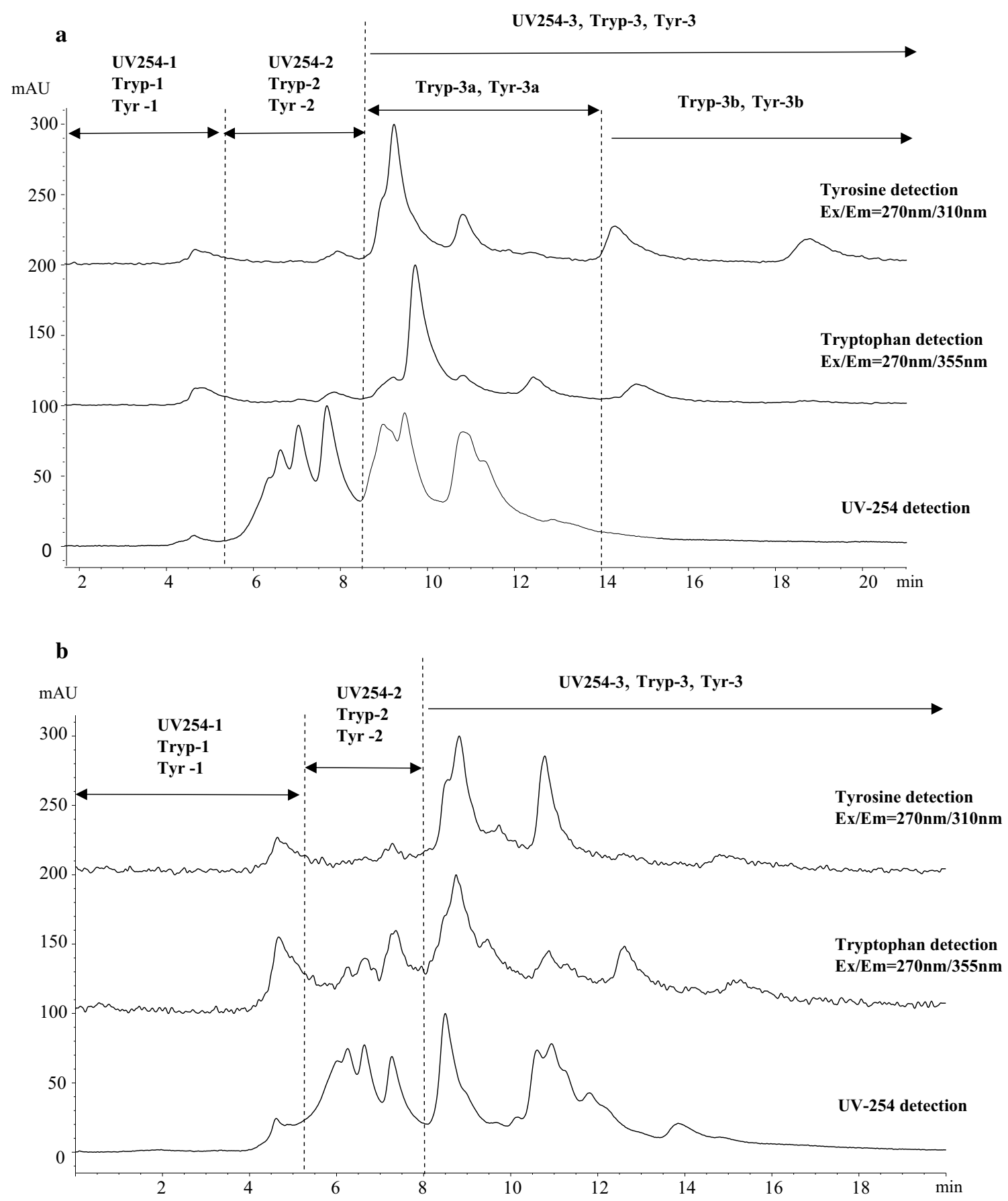

Fig. 1 Chromatograms at different detections of BWE (a) and GWE (b). Eluent: $0.02 \mathrm{M} \mathrm{CH}_{3} \mathrm{COONa}, \mathrm{pH}$ : 7.2, mAU (milliAmpere Units). Effluent characteristics: BWE: TKN $=164 \mathrm{mg} / \mathrm{L}, \mathrm{BOD}-7=543 \mathrm{mg} / \mathrm{L}$,

and numerous molecules. The chromatograms are complex because of numerous organic molecules and extracellular polymers excreted by viable cells in the wastewater, a finding that agrees with a previous study on extrapolymeric substances extracted from anaerobic sludge (Bahtia et al.
$\mathrm{COD}=1500 \mathrm{mg} / \mathrm{L}, \quad \mathrm{DOC}=170 \mathrm{mg} / \mathrm{L} ; \mathrm{GWE}: \mathrm{TKN}=35.4 \mathrm{mg} / \mathrm{L}$, BOD-7 $=509 \mathrm{mg} / \mathrm{L}, \mathrm{COD}=980 \mathrm{mg} / \mathrm{L}, \mathrm{DOC}=244 \mathrm{mg} / \mathrm{L}$

2013). We divided the chromatograms into three regions: region 1 of fractions eluted near a void volume of $4.5 \mathrm{~mL}$, region 2 of fractions eluted between $5 \mathrm{~min}$ and $8.25 \mathrm{~min}$, and region 3 of fractions eluted after $8.25 \mathrm{~min}$. (Figure 1). For BWE samples, region 3 fluorescence signals 
were divided into two additional sub-regions: region $3 \mathrm{a}$ of peaks between $8.25 \mathrm{~min}$ and $14 \mathrm{~min}$ and region $3 \mathrm{~b}$ of peaks eluted after $14 \mathrm{~min}$. (Figure 1). The chromatograms were divided into the above three regions because region 1 peaks were distinct from region 2 peaks and were probably influenced by secondary, repulsive interactions (Ricker and Sandoval 1996; Pelekani et al. 1999; Bouvier and Koza 2014). Region 2 peaks are regularly observed in natural waters, such as surface and ground waters, and are considered 'humic' compounds (Peuravuori and Pihlaja 1997; Szabo and Tuhkanen 2010). Region 3 peaks are not observed in natural water samples but are seen in complex wastewater effluents, and their late elution is probably due to secondary attractive interactions within the column (Szabo et al. 2016). Sub-region 3b peaks (one or two peaks) were detected only by fluorescence detection in BWE, and by separating the peaks, we tried to determine their nature.

The ChrInds are peak areas expressed in $\mathrm{mAU}^{*}$ min of different regions of different detections. In this way, 13 'individual' ChrInds could be distinguished: UV254-1, UV254-2, UV254-3, Tryptophan-1 (Tryp-1), Tryp-2, Tryp-3, Tryp-3a, Tryp-3b, Tyrosine-1 (Tyr-1), Tyr-2, Tyr-3, Tyr-3a, Tyr-3b. In addition, three 'sum-ChrInds' were calculated by summing up all the peaks of the corresponding detection, respectively, UV254, Tryp and Tyr.

The minimum, maximum and mean values of the different ChrInds are given in Table 2. As expected, GWE samples had lower ChrInd values than BWE samples. The mean values of GWE were from $8.4 \%$ (Tyr-1) to $62.9 \%$ (Tryp-2) of those of BWE values.

The data on BWE and GWE differ because of their different compositions (BWE contains additional faeces, urine and toilet paper), and as such are not directly comparable. Therefore, we calculated the Spearman rank correlation coefficients between ChrInd and conventional indicators separately for BWE and GWE (Table 3).

Table 3 shows that the organic matter indicators of the effluents (BOD-7, COD and DOC) correlate significantly with all ChrInds, except for GWE regions 1 and 2. Region 1 fractions were eluted near the void volume of $4.6 \mathrm{~min}$ and, according to SEC theory, were influenced by repulsive electrostatic interactions or had large molecular weight, around $10^{6}$ Da (Irvine 1997; Ricker and Sandoval 1996; Pelekani et al. 1999; Specht and Frimmel 2000). The conventional indicators and region 1 ChrInd for GWE correlated poorly because region 1 peaks were absent in 8 (53\%) GWE samples but only in 5 (9\%) BWE samples. Region 2 showed 'humic-type' fractions within the calibration range, which are naturally present in waters bodies, and are traditionally detected by UV254 (Peuravuori and Pihlaja 1997; Specht and Frimmel 2000; Szabo et al. 2008). In our study, among the three detections used, UV254 was also the best in detecting region 2 peaks. UV254 region 2 fractions were present in all of the analysed WWE samples, whereas fluorescence detected mostly the lowest molecular weight fractions in region 2. Fractions eluted at around $7.6 \mathrm{~min}$ represent humic molecules, inorganic nitrate (Szabo and Tuhkanen

Table 2 Chromatographic indicators (ChrInd) of mixed (a) and grey (b) wastewater effluents

\begin{tabular}{|c|c|c|c|c|c|c|c|c|c|c|}
\hline \multirow{2}{*}{$\begin{array}{l}\text { Chromatographic indica- } \\
\text { tors ChrInd (mAU*min) }\end{array}$} & \multicolumn{5}{|l|}{$\mathrm{a}$} & \multicolumn{5}{|l|}{ b } \\
\hline & \# & Minimum & Maximum & Mean & SD & \# & Minimum & Maximum & Mean & SD \\
\hline UV-254 & 54.0 & 23.8 & 2008.9 & 725.4 & 380.2 & 15.0 & 101.6 & 993.3 & 281.5 & 214.0 \\
\hline Tryp & 54.0 & 8.8 & 1053.3 & 362.3 & 251.0 & 15.0 & 2.0 & 263.3 & 89.6 & 75.3 \\
\hline Tyr & 54.0 & 0.0 & 1066.9 & 350.5 & 272.3 & 15.0 & 1.0 & 249.1 & 60.5 & 63.1 \\
\hline UV254-1 & 54.0 & 0.0 & 47.2 & 14.3 & 10.4 & 15.0 & 0.0 & 36.0 & 3.5 & 9.1 \\
\hline UV254-2 & 54.0 & 15.5 & 1075.9 & 319.1 & 179.1 & 15.0 & 27.0 & 379.7 & 130.3 & 83.3 \\
\hline UV254-3 & 54.0 & 8.3 & 995.1 & 391.8 & 233.5 & 15.0 & 17.0 & 577.6 & 147.6 & 136.6 \\
\hline Tryp-1 & 54.0 & 0.0 & 117.0 & 29.0 & 22.6 & 15.0 & 0.0 & 35.4 & 5.7 & 9.4 \\
\hline Tryp-2 & 54.0 & 0.0 & 114.9 & 37.9 & 21.3 & 15.0 & 0.0 & 168.0 & 23.8 & 42.0 \\
\hline Tryp-3 & 54.0 & 8.8 & 905.6 & 294.9 & 218.2 & 15.0 & 0.0 & 173.2 & 60.0 & 48.8 \\
\hline Tryp-3a & 54.0 & 8.8 & 815.3 & 276.8 & 202.0 & 15.0 & 0.0 & 0.0 & 0.0 & 0.0 \\
\hline Tryp-3b & 54.0 & 0.0 & 90.3 & 18.1 & 23.1 & 15.0 & 0.0 & 0.0 & 0.0 & 0.0 \\
\hline Tyr-1 & 54.0 & 0.0 & 70.8 & 19.8 & 14.3 & 15.0 & 0.0 & 9.6 & 1.7 & 3.1 \\
\hline Tyr-2 & 54.0 & 0.0 & 116.8 & 20.4 & 17.3 & 15.0 & 0.0 & 11.3 & 2.9 & 3.4 \\
\hline Tyr-3 & 54.0 & 0.0 & 1038.7 & 315.2 & 253.4 & 15.0 & 0.0 & 203.2 & 52.9 & 54.2 \\
\hline Tyr-3a & 54.0 & 0.0 & 852.3 & 226.9 & 185.8 & 15.0 & 0.0 & 0.0 & 0.0 & 0.0 \\
\hline Tyr-3b & 53.0 & 0.0 & 330.2 & 85.5 & 93.6 & 15.0 & 0.0 & 0.0 & 0.0 & 0.0 \\
\hline
\end{tabular}




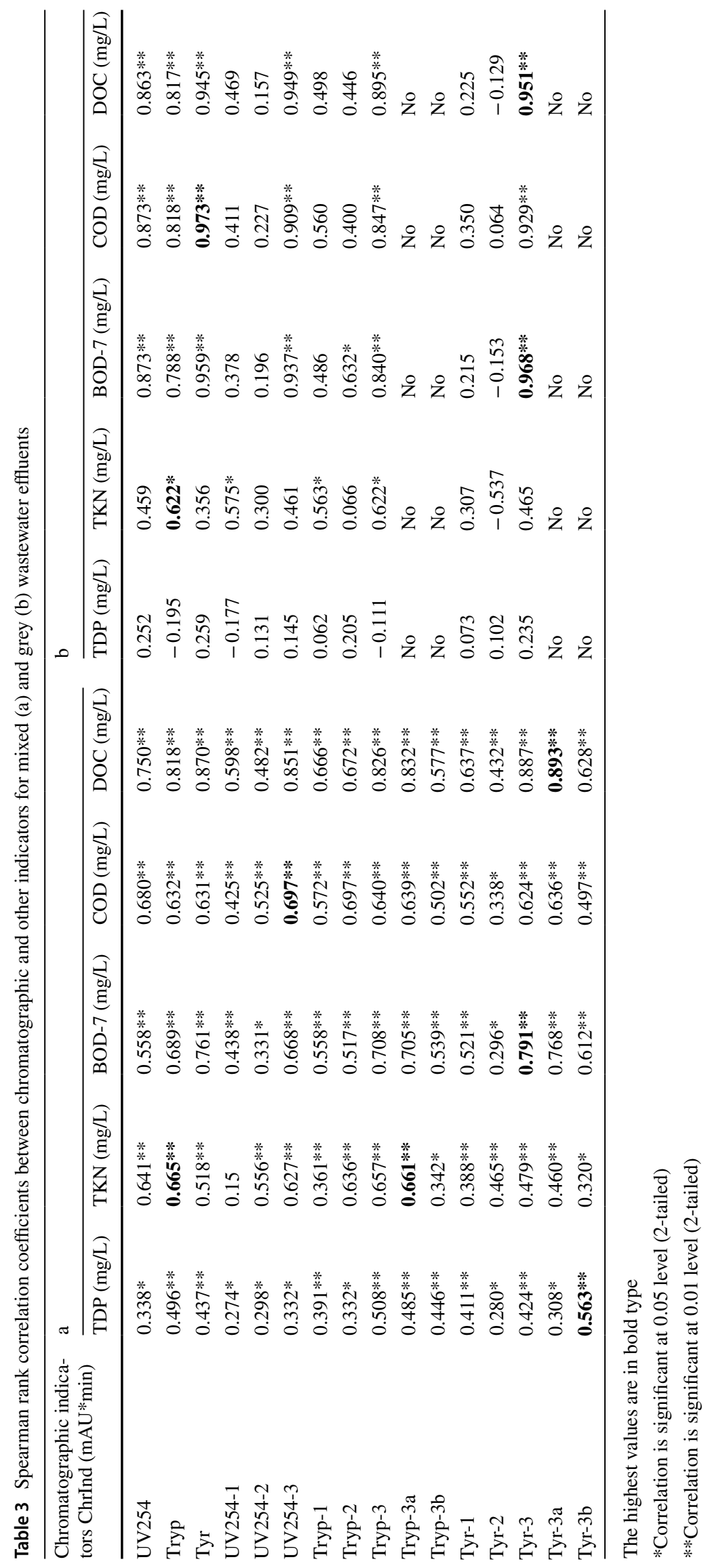


2010), and some organic molecules with tryptophan-like and tyrosine-like fluorophores (Fig. 1).

For region 2, tyrosine signals were weaker than tryptophan signals, especially for GWE with 7 (47\%) samples having no tyrosine fraction in this region. This explains the non-significant correlations between Tyr-2 and conventional organic indicators for GWE. For BWE region 2 ChrInd, UV254-2, Tryp-2 and Tyr-2 fractions correlated better with COD and DOC than with BOD because of the relatively poor biodegradability of the humic matter (Leenheer and Croué 2003; Marschner and Kalbitz 2003).

Region 3 covered fractions UV254-3, Tryp-3, Tryp-3a, Tryp-3b, Tyr-3, Tyr-3a and Tyr-3b. These fractions, eluted after the permeation volume, are influenced, according to SEC theory, by secondary interactions: strong ionic or strong hydrophobic attraction between column material and fraction molecules (Irvine 1997; Ricker and Sandoval 1996; Pelekani et al. 1999; Specht and Frimmel 2000; Janoš and Zatrepálková 2007). Correlating significantly and strongly with the conventional organic matter indicators (Table 3), the fractions of region 3 are potentially the best surrogates for organic matter indicators.

BOD-7 and DOC correlate surprisingly strongly with Tryp-3, Tryp-3a, Tyr-3 and Tyr-3a fractions for both types of effluents, showing that these fractions comprise biodegradable compounds, which are also reliably measured by DOC. Similar results have been reported on tyrosine- and tryptophan-type components of the excitation-emission matrix of municipal wastewater, sampled at different purification phases and correlating best with DOC (Yu et al. 2014). The slightly stronger correlation coefficients of DOC over those of BOD-7 are possible because BOD-7 depends on the microbial diversity of the sample, which varies from sample to sample and affects BOD-7 values (Jouanneau et al. 2014).

For BWE, COD showed a lower correlation coefficient for region 3 fractions Tryp-3 and Tyr-3 than BOD-7 and DOC and a consistent correlation with all the chromatographic fractions, probably because of oxidant consumption during COD measurement, which reduced inorganic compounds in the anaerobic effluents not detectable by HPLC-SEC. One such reducing component is the reduced form of $\mathrm{N}\left(\mathrm{NH}_{3} / \mathrm{NH}_{4}{ }^{+}\right)$, which originates from urine (Udert et al. 2003). For GWE, all BOD-7, COD, and DOC correlated strongly with region 3 fractions in all detections, showing that these effluents contain less reducing inorganic compounds than BWE effluents, which is obvious since greywater effluents contain no urine.

TKN (Kjeldahl) correlated significantly with all ChrInds, except for one (UV254-1) for BWE. For GWE, there were only four significant correlations (Tryp, UV254-1, Tryp-1 and Tryp-3) (Table 2). In general, TKN correlated better with tryptophan-like fractions (Tryp, Tryp-1, Tryp-2, Tryp-3 and Tryp-3a), probably because the tryptophan molecule, a part of the compounds detected in tryptophan detection, contains two $\mathrm{N}$ atoms, whereas the tyrosine molecule contains only one $\mathrm{N}$ atom. The sum-ChrInd (UV254, Tryp and Tyr) correlated better than 'individual' ones, suggesting that $\mathrm{N}$ is present in all fractions. In addition, the uncertainties related to TKN measurements by the Kjeldahl method may contribute to relatively weak correlations.

TDP correlated significantly but weakly with all the ChrInd of BWE and insignificantly with any ChrInd of GWE (Table 3), probably because of the low amount of TDP left in GWE (Table 1). Interestingly, for BWE, TDP correlated most strongly with Tyr-3b, which represents the last two fractions eluted after 14 min for the BWE samples (Fig. 1a). This suggests that these fractions contain most of the dissolved phosphorous left in BWE. Moreover, the interaction between the column material and these late eluted peaks may be strongly hydrophobic, as supported by a previous study, which found that most dissolved organic phosphorous belonged to the hydrophobic fraction of the organic matter dissolved in wastewater effluents (Qin et al. 2015).

\section{Linear regression}

To assess the quantitative relationship between conventional indicators and ChrInd, linear regression was done on a particular conventional indicator and the corresponding ChrInd with which it correlated the strongest (Fig. 2, bold in Table 3).

Because regression showed high $R^{2}$ values for greywater effluent BOD-7-Tyr-3, DOC-Tyr-3 and COD-Tyr, the equations can be used to reliably assess BOD-7, DOC and COD values of greywater effluents from Tyr-3 and Tyr data. For BWE, we excluded one outlier for BOD-7 and two outliers for COD, thereby gaining increased $R^{2}$ values for the corresponding regression equations and allowing assessment of approximate values of BOD-7, DOC, and COD of BWE from Tyr-3, Tyr-3a, and UV-3 data.

TKN showed weaker correlations with ChrInd than with the conventional organic indicators. However, the regression equations between TKN-Tryp gained by excluding two outliers from greywater effluents and four outliers from BWE can be used to approximate TKN values from Tryp data. 


\section{Grey}
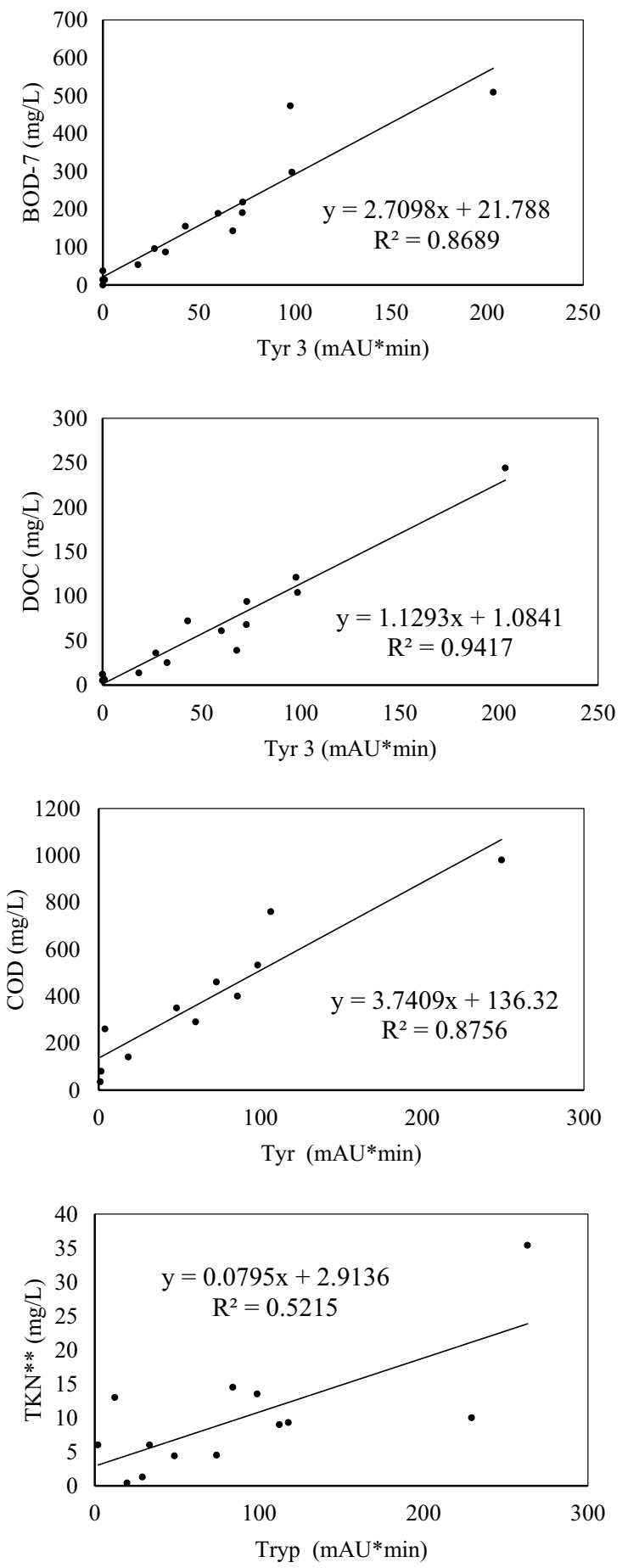

Mixed
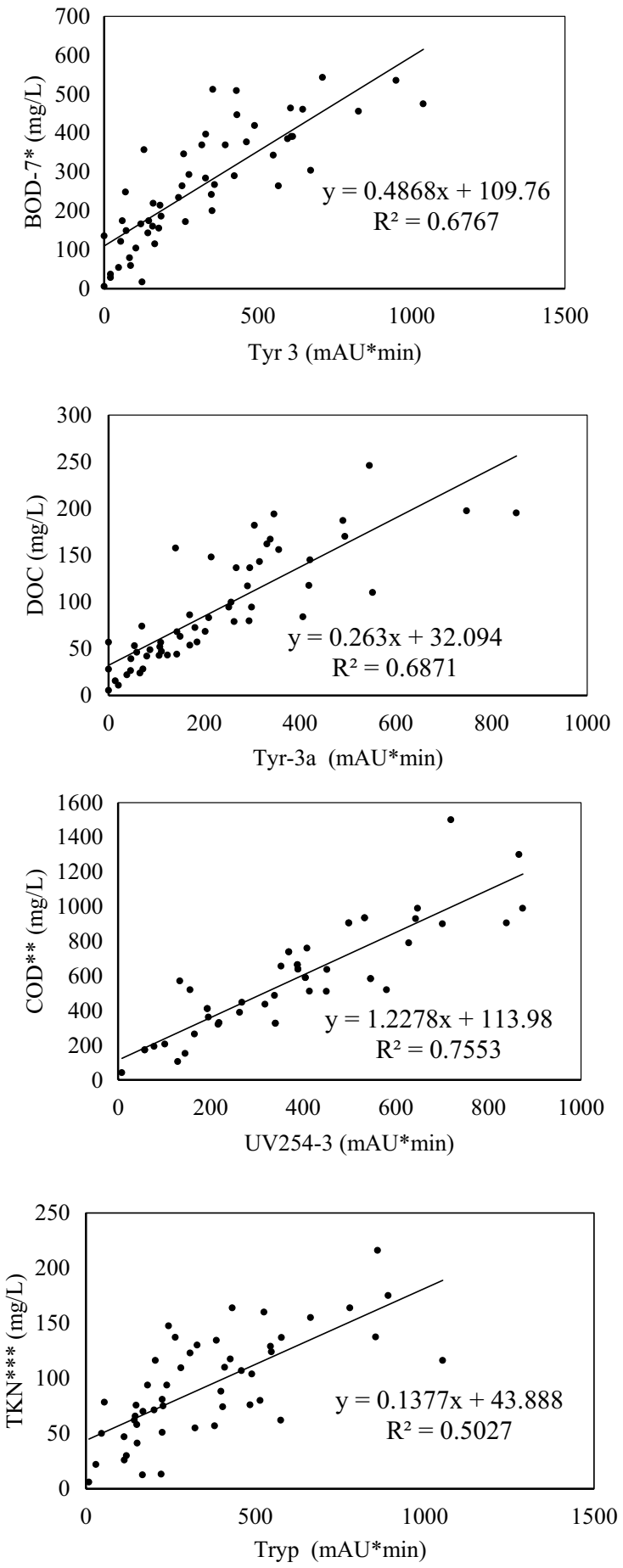

Fig. 2 Linear regression between conventional organic quality indicators and chromatographic fractions with which they best correlate. *One outlier excluded from regression; **two outliers excluded from regression; ***four outliers excluded from regression

\section{Conclusion}

Besides the current practice of measuring MW, our results show that HPLC-SEC can also be used to assess BOD and other conventional organic matter indicators (COD, DOC) of wastewater effluents. The TSK-GEL G3000SW silica gel column and Na-acetate eluent $0.02 \mathrm{M}$ provided good separation of dissolved organic matter components from complex and less complex onsite wastewater effluents. The most important advantage of this method is that it gives us insight into 
the composition of DOM by differentiating the major organic components in water samples as fractions rather than as sum parameters given by COD, BOD and DOC. Additional advantages are short analysis time and no use of harmful chemicals.

A large part of wastewater fractions was eluted over the permeation volume, where secondary interactions with the column material predominated. The last two fractions, seen only in BWE, eluted at around $15 \mathrm{~min}$ and $19 \mathrm{~min}$, were probably affected by strong attractive hydrophobic interaction. Multiple detection with UV254 absorption and tryptophanand tyrosine-like fluorescence showed well-separated regions in the chromatograms, which correlated with the conventional water quality indicators and could be used as their surrogates.

In the chromatograms, region 3 or parts of it (Tyr-3, Tyr3a and UV254-3) described best the organic matter indicators (BOD-7, DOC and COD). The BOD-7 values of BWE and GWE correlated best with Tyr-3, that is, the sum of the fractions eluted after $8.25 \mathrm{~min}$.

The regressions obtained from our data allow reliable assessment of the BOD-7 of GWE and approximation of the BOD-7 of BWE. This is an important finding, because an HPLC-SEC run of one sample requires only a $1 / 2 \mathrm{~h}$ as opposed to BOD-7 lasting for 7 days. DOC showed the best correlation with Tyr-3 for GWE and with Tyr-3a of fractions between 8.25 and 14 min for BWE. On the other hand, COD correlated best with Tyr (all tyrosine-type fractions) for GWE and with UV254-3 for BWE. The corresponding regression equations can be used to reliably calculate DOC and COD for GWE and to approximate them for BWE.

TKN correlated best with tryptophan-like fractions, but regression gave an $R^{2}$ value of 0.52 only for both types of wastewater, showing that Tryp (sum of all tryptophan-like fractions) could be used only to roughly estimate the TKN value of wastewater effluents.

Acknowledgements This research was supported (H. Szabo) by the Maj and Tor Nessling Foundation, the Finnish Cultural Foundation, and Maa-ja vesitekniikan tuki. We thank MSc. Tanja Hyttinen for her help with the sampling and analysis of the conventional water quality indicators.

Open Access This article is distributed under the terms of the Creative Commons Attribution 4.0 International License (http://creativeco mmons.org/licenses/by/4.0/), which permits unrestricted use, distribution, and reproduction in any medium, provided you give appropriate credit to the original author(s) and the source, provide a link to the Creative Commons license, and indicate if changes were made.

\section{References}

Almomani FA, Khraisheh AM (2016) Treatment of septic tank effluent using moving-bed biological reactor: kinetic and biofilm morphology. Int J Environ Sci Technol 13:1917-1932
Bahtia D, Bourven I, Simon S, Bordas F, van Hullenbush E, Rossano S, Lens PNL, Guibaud G (2013) Fluorescence detection to determine proteins and humic-like substances fingerprints of exopolymeric substances (EPS) from biological sludges performed by size-exclusion chromatography (SEC). Bioresour Technol 131:159-165

Bouvier ESP, Koza SP (2014) Advances in size-exclusion separations of proteins and polymers by UHPLC. Trends Anal Chem 63:85-94

Brandes M (1978) Characteristics of effluents from gray and black water septic tanks. J (Water Pollut Control Fed) 50:2547-2559

Carstea EM, Bridgeman J, Baker A, Reynolds DM (2016) Fluorescence spectroscopy for wastewater monitoring: a review. Water Res 95:205-219

Chamarro E, Marco A, Espulgas S (2001) Use of fenton reagent to improve organic chemical biodegradability. Water Res 35:1047-1051

Corbett DR, Dillon K, Burnett W, Schaefer G (2002) The spatial variability of nitrogen and phosphorous concentration in a sand aquifer influenced by onsite sewage treatment and disposal systems: a case study on St. George Island, Florida. Environ Pollut 117:337-345

Eveborn D, Kong D, Gustafsson JP (2012) Wastewater treatment by soil infiltration: long-term phosphorous removal. J Contam Hydrol 140-141:24-33

Figueruelo J, García-Lopera R, Falo M, Abad C, Campos A (2004) Study on resolution capacity and secondary mechanisms of three different TSK gels for organic SEC. J Chromatogr Sci 42:524-530

Garcia SN, Clubbs RL, Stanley JK, Sheffe B, Yelderman JC Jr, Brooks BW (2013) Comparative analysis of effluent water quality from a municipal treatment plant and two on-site wastewater treatment systems. Chemosphere 92:38-44

Her N, Amy G, McKnight D, Sohn J, Yoon Y (2003) Characterization of DOM as a function of MW by fluorescence EEM and HPLC-SEC using UVA, DOC, and fluorescence detection. Water Res 37:4295-4303

Irvine GB (1997) Size-exclusion high-performance liquid chromatography of peptides: a review. Anal Chim Acta 352:387-397

Janoš P, Zatřepálková I (2007) High-performance size-exclusion chromatography of humic substances on the hydroxyethyl methacrylate column. J Chromatogr A 1160:160-165

Jenssen PD, Krogstad T, Paruch AM, Maehlum T, Adam K, Arias CA, Heistad A, Jonsson L, Hellstrm D, Brix H, Yli-Halla M, Vråle L, Valve M (2010) Filter bed systems treating domestic wastewater in the Nordic countries-performance and reuse of filter media. Ecol Eng 36:1651-1659

Jouanneau S, Recoules L, Durand MJ, Boukabavhe A, Picot V, Primault Y, Lakel A, Sengelin M, Barillon B, Thounad G (2014) Methods for assessing biochemical oxygen demand (BOD): a review. Water Res 49:62-82

Leenheer JA, Croué JP (2003) Characterizing dissolved aquatic organic matter. Environ Sci Technol A 37(1):18A-26A

Marschner B, Kalbitz K (2003) Controls of bioavailability and biodegradability of dissolved organic matter in soils. Geoderma 113:211-235

O'Launaigh ND, Gill LW, Misstear BDR, Johnston PM (2012) The attenuation of microorganisms in on-site wastewater effluent discharged into highly permeable subsoils. J Contam Hydrol 142-143:126-139

Pasztor I, Thury P, Pulai J (2009) Chemical oxygen demand fractions of municipal wastewater for modelling of wastewater treatment. Int J Environ Sci Technol 6:51-56

Pelekani C, Newcombe G, Snoeyink V, Hepplewhite C, Assemi S, Beckett R (1999) Characterization of natural organic matter 
using high performance size exclusion chromatography. Environ Sci Technol 33:2807-2813

Peuravuori J, Pihlaja K (1997) Molecular size distribution and spectroscopic properties of aquatic humic substances. Anal Chim Acta 337:133-149

Prasse C, Stalter D, Schulte-Oehlmann U, Oehlmann J, Ternes TA (2015) Spoilt for choice: a critical review on the chemical and biological assessment of current wastewater treatment technologies. Water Res 87:237-270

Qin C, Liu H, Liu L, Smith S, Sedlak DL, Gu AZ (2015) Bioavailability and characterization of dissolved organic nitrogen and dissolved organic phosphorous in wastewater effluents. Sci Total Environ 511:47-53

Ricker RD, Sandoval LA (1996) Fast, reproducible size-exclusion chromatography of biological macromolecules. J Chromatogr A 743:43-50

Specht CH, Frimmel FH (2000) Specific interactions of organic substances in size-exclusion chromatography. Environ Sci Technol 34:2361-2366

Szabo HM, Tuhkanen T (2010) The application of HPLCSEC for the simultaneous characterization of NOM and nitrate in well waters. Chemosphere 80:779-786

Szabo HM, Lindfors I, Tuhkanen T (2008) NOM from catchment to drinking water-case pori waterworks from Finland. Water Sci Technol Water Supply 8:681-690
Szabo HM, Lepistö R, Tuhkanen T (2016) HPLC-SEC: a new approach to characterize complex wastewater effluents. Int J Environ Anal Chem 96:257-270

Tanik A, Ozlap D, Seker DZ (2013) Practical estimation and distribution of diffuse pollutants arising from a watershed in Turkey. Int J Environ Sci Technol 10:221-230

Udert KM, Larsen TA, Biebow M, Gujer W (2003) Urea hydrolysis and precipitation dynamics in a urine-collecting system. Water Res 37:2571-2582

Withers PJA, May L, Jarvie HP, Jordan P, Doody D, Foy RH, Bechmann M, Cooksley S, Dils R, Deal N (2012) Nutrient emission to water from septic tank systems in rural catchments: uncertainties an implications for policy. Environ Sci Policy 24:71-82

Wu Q, Li C, Wang W, He T, Hu H, Du Y, Wang T (2016) Removal of fluorescence and ultraviolet absorbance of dissolved organic matter in reclaimed water by solar light. J Environ Sci 43:118-127

Yu H, Song Y, Liu R, Pan H, Xiang L, Qian F (2014) Identifying changes in dissolved organic matter content and characteristics by fluorescence spectroscopy coupled with self-organizing map and classification and regression tree analysis during wastewater treatment. Chemosphere 113:79-86 